\title{
The impact of COVID-19 on neurosurgeons and the strategy for triaging non-emergent operations: a global neurosurgery study
}

\author{
Walter C. Jean ${ }^{1,2} \cdot$ Natasha T. Ironside ${ }^{3} \cdot$ Kenneth D. Sack ${ }^{1} \cdot$ Daniel R. Felbaum ${ }^{2,4} \cdot$ Hasan R. Syed $^{2,3}$
}

Received: 6 April 2020 / Accepted: 7 April 2020 / Published online: 21 April 2020

(C) Springer-Verlag GmbH Austria, part of Springer Nature 2020

\begin{abstract}
Object The COVID-19 pandemic has disrupted all aspects of society globally. As healthcare resources had to be preserved for infected patients, and the risk of in-hospital procedures escalated for uninfected patients and staff, neurosurgeons around the world have had to postpone non-emergent procedures. Under these unprecedented conditions, the decision to defer cases became increasingly difficult as COVID-19 cases skyrocketed.

Methods Data was collected by self-reporting surveys during two discrete periods: the principal survey accrued responses during 2 weeks at the peak of the global pandemic, and the supplemental survey accrued responses after that to detect changes in opinions and circumstances. Nine hypothetical surgical scenarios were used to query neurosurgeons' opinion on the risk of postponement and the urgency to re-schedule the procedures. An acuity index was generated for each scenario, and this was used to rank the nine cases.

Results There were 494 respondents to the principal survey from 60 countries. 258 (52.5\%) reported that all elective cases and clinics have been shut down by their main hospital. A total of 226 respondents $(46.1 \%)$ reported that their operative volume had dropped more than $50 \%$. For the countries most affected by COVID-19, this proportion was $54.7 \%$. There was a high degree of agreement among our respondents that fast-evolving neuro-oncological cases are non-emergent cases that nonetheless have the highest risk in postponement, and selected vascular cases may have high acuity as well.

Conclusion We report on the impact of COVID-19 on neurosurgeons around the world. From their ranking of the nine case scenarios, we deduced a strategic scheme that can serve as a guideline to triage non-emergent neurosurgical procedures during the pandemic. With it, hopefully, neurosurgeons can continue to serve their patients without endangering them either neurologically or risking their exposure to the deadly virus.
\end{abstract}

Keywords Global neurosurgery $\cdot$ COVID-19 $\cdot$ Pandemic $\cdot$ Social media

This article is part of the Topical Collection on Neurosurgery general

Electronic supplementary material The online version of this article (https://doi.org/10.1007/s00701-020-04342-5) contains supplementary material, which is available to authorized users.

Walter C. Jean

wjean@mfa.gwu.edu

1 Department of Neurological Surgery, George Washington University, 2150 Pennsylvania Ave NW 7th floor, Washington DC 20037, USA

2 Global Brainsurgery Initiative, Washington DC, USA

3 Department of Neurosurgery, University of Virginia, Charlottesville, VA, USA

4 Department of Neurosurgery, Georgetown University, Washington DC, USA

$\begin{array}{ll}\text { Abbreviations } \\ \text { ACS } & \text { American College of Surgeons } \\ \text { AI } & \text { acuity index } \\ \text { Ave } & \text { average } \\ \text { AVM } & \text { arteriovenous malformation } \\ \text { CI } & \text { confidence interval } \\ \text { EANS } & \text { European Association of Neurological Surgery } \\ \text { GBM } & \text { glioblastoma multiforme } \\ \text { LMIC } & \text { low-to-middle-income countries } \\ \text { Met } & \text { metastasis } \\ \text { USA } & \text { United States of America } \\ \text { VS } & \text { vestibular schwannoma }\end{array}$




\section{Introduction}

As the novel coronavirus (SARS-COV-2) swept across the globe, the COVID-19 pandemic has disrupted all aspects of society, with a breadth and intensity unfathomable for those born after the last World War. With relatively few neurological manifestations [1-3], neurosurgeons have been sheltered from "frontline action" that is battering subspecialists in emergency, intensive care and pulmonary medicine, but nevertheless, the practice of neurosurgery is yet susceptible to the havoc that COVID-19 has wrought. On a systems level, teams of neurosurgeons have been re-deployed as intensivists, neurosurgical patients have been re-housed in COVID-clean wards, protocols have been implemented to test patients ahead of neurosurgical procedures, and hospital systems have been reorganized to "hub-and-spoke" configurations to segregate neurosurgery to designated centers [4-6].

On a personal level, neurosurgeons have also had to make adjustments. As hospitals tried to conserve precise resources for the tsunami of patients, governments worked to protect uninfected citizens, and medical societies strived to support physicians and nurses, neurosurgeons have been mandated to drastically alter their practices as the entire world mobilized to combat SARS-CoV-2. On March 13, 2020, the American College of Surgeons (ACS) issued an unprecedented recommendation to "minimize, postpone or cancel electively scheduled operations" [7]. As COVID-19 cases skyrocketed in the USA that week, the American Hospital Association and Center for Medicare and Medicaid Services quickly followed the ACS and issued similar recommendations [8-10]. Intuitively rational, medically sound, and worded respectful of the decision-making skills well-honed over decades of training, these recommendations nonetheless confounded neurosurgeons as they left the definition of "elective" to each individual practitioner.

On a daily basis, neurosurgeons identify life-threatening emergencies, and hardly any would argue, for example, that a healthy patient with a grade I aneurysmal subarachnoid hemorrhage can wait for treatment even during a pandemic. Similarly, with those aforementioned sharp decision-making skills, neurosurgeons can readily determine that, an incidentally discovered $1 \mathrm{~cm}$ vestibular schwannoma, can wait for treatment until SARS-CoV-2 has been thoroughly defeated. However, between these two examples are the problematic cases, for which the risk of postponement is left to the unknowable pace of disease progression, or worse, dependent only on chance.

We designed this survey study to (a) determine the degree to which the current pandemic has disrupted the practice of neurosurgeons around the globe and across all types of practice and (b) to discover any pattern of thought or decisionmaking process that leads neurosurgeons to decide what operation can be postponed and for how long. With the assumption that neurosurgeons are well-trained to recognize the extremes of the "elective-to-emergent" spectrum, we concentrated on the middle, where the decision to postpone is the most challenging.

\section{Methods}

\section{Participation in the study}

For this study, the aim was to "spot-check" and compare the worldwide impact of COVID-19 on neurosurgical practices. Neurosurgeons around the world were invited to participate in the study survey between March and April 2020. The principal study started 2 days after the ACS issued its recommendation (March 16) and lasted for 2 weeks. As the pandemic evolved rapidly, a supplemental study was designed to capture the changes in hospitals' responses and surgeons' perspectives. This phase was "live" from March 23 to April 3. Using the international contact network of Global Brainsurgery Initiative, and relying especially on the senior author's (WCJ) social media following, the invitation to complete the survey was broadcasted over social media, through Neurosurgery-specific groups/clubs/channels on platforms which included Facebook, Instagram, Linkedin, Twitter, and Whatsapp. The survey relied on voluntary self-reporting. Although the survey was accessible to anyone with internet access, the first page of it clearly stated that respondents must be a neurosurgeon, trainees included.

In strict adherence to the US federal regulation for IRB exemption 45 CFR 36104 (d) (4, ii), once a response was accepted into the study, it was immediately and permanently anonymized. All information which can identify the respondent, which, in this survey is only the email that was left to the respondent as an option to provide, was detached from the rest of the survey answers and permanently deleted. The response was then given a subject number for identification during the study.

\section{Survey design}

A survey was specifically designed for this study. The principal study consisted of 20 questions written in English, the first 11 of which queried the respondents' practice setting, country, current societal and practice conditions relevant to the pandemic, and his or her opinion about the shutdown of surgeries. The degree to which cancelation of elective cases has been applied by hospital policy, or should be applied according to personal opinion, was queried with 4 tiers: none, at surgeons' discretion, some, and all cases. Nine questions formed the second half of the survey, and these pertained to hypothetical case scenarios and the risk of postponing surgery for each. 
In the supplement of the survey, respondents were asked whether they (personally), the country or the hospital has changed policy since the start of the study on March 16, 2020. The same nine hypothetical case scenarios formed the second part of the supplemental phase, but this time, the question pertained to the length of reasonable postponement. Both phases for the study were intended to be anonymous, and selfidentification of the respondents was voluntary. Participation in either phase may be mutually exclusive.

\section{An acuity rank and algorithm}

Nine hypothetical case scenarios were presented to the respondents (Appendix 1 in the ESM). For each case, respondents in the principal study were asked to stratify the risk of postponing surgery into four tiers from none to severe. There were 448 respondents to these questions. During analysis, a "risk score" was generated by converting each response into a number: from 1 for "no risk," to 4 for "cannot postpone." In the supplement, the same scenarios were presented, this time asking for how much longer than a week the operation can be reasonably put off. There were 315 respondents. An "urgency score" was generated by converting each response into a number from 1 to 5 . Average scores were calculated, and the average "risk score" was multiplied by the "urgency score" for each case to generate an "acuity index" (AI). The nine cases were then ranked to produce the acuity rank order for the study.

The "acuity index" was calculated another way to check for internal consistency. Since the identity of the respondent is not required for completion of the survey, leaving an email address on either phase was voluntary. However, 166 respondents left their emails on both phases, and we matched up all their responses. For these, we calculated a personal acuity index (PAI) by multiplying the individual's risk score for each question in the principal phase to the urgency score in the supplemental phase. The average of the product $\left(\mathrm{PAI}_{166}\right)$ was generated for each of the nine scenarios, ranked and compared to the total cohort.

\section{Statistical analysis}

Descriptive statistics were used to characterize the overall responses from the study cohort. Continuous variables were reported as the mean and were compared using a 2-tailed Student's $t$ test. Categorical variables were reported as proportions and were compared using $\chi^{2}$ test. Univariable ordinal and logistic regression analyses to identify predictors of personal view and hospital response were performed. In addition, multivariable ordinal and logistic regression analyses, initially including all potential predictor variables, with stepwise backward elimination of non-contributory variables $(p>0.10)$, to identify independent predictors of personal view and hospital response were also performed. For each of the hypothetical questions, percentage agreement was calculated by computing the number of rater scores with exact agreement divided by the total number of possible rater scores.

All tests were 2 -sided, and a $p$ value of less than 0.05 was considered statistically significant. Statistical analysis was performed using Excel (version 15.36, 2017, Microsoft, Redmond WA) and Stata (version 15.1, StataCorp., College Station TX).

\section{Results}

There were 494 respondents to the principal survey from 60 countries, with 55 respondents from countries designated by the World Bank as "low-to-middle-income" countries (Table 1). Two hundred and ninety-nine (61\%) were from the ten countries $\left(\mathrm{C}_{10}\right)$ most affected by the pandemic: the USA, Italy, China, Spain, Germany, France, the UK, Switzerland, Netherlands, and South Korea. By the end of the principal phase, all these countries had recorded more than 9000 cases. Globally, there were 182,000 cases at the start of the study on March 16, 2020. By the end of the principal phase, this number has jumped to 738,000 , and at the end of the supplemental phase (April 3), it was 1.2 million [12]. The study period corresponded to the peak of the pandemic in Western Europe.

A majority of the respondents of the principal study are early-career neurosurgeons (Fig. 1a) and 102 (20.7\% of all respondents) categorized their main practice as "for-profit" (Fig. 1b). Four hundred and thirty-seven (88.8\%) reported at least some disruption of their practice caused by the pandemic, with 52.2\% saying that all elective cases and clinics have been shut down by hospital or practice policy (Fig. 1c). When asked for their opinion, even more, 302 (61.4\%) neurosurgeons, thought that their elective practice ought to be shut down totally (Fig. 1d). A total of 226 respondents (46.1\%) reported that their operative volume had dropped more than $50 \%$. For the COVID-ravaged $\mathrm{C}_{10}$ countries, this proportion is even higher, at $54.7 \%$ (Fig. 1e).

\section{Effect of COVID-19 case volume and policy of social distancing}

High prevalence of COVID-19 infections and governmental policy to close shops and restaurants were strong predictors of hospital policy to cancel elective cases and clinics on univariate analysis (Table $2, p<.001$ ), but the influence of case numbers did not reach significance in multi-variate analysis. As expected, there was a significant correlation between hospital policy and the surgeon's self-reported decrease in operative volume (Table $2, p<.001$ ). Higher number of COVID-19 cases was also a predictor of neurosurgeons' views in support 
Table 1 Count of all respondents, grouped by country, and arranged in descending order. Countries denoted by an asterisk are designated as "low-to-middleincome countries" by the World Bank [11]

\begin{tabular}{|c|c|}
\hline Country & $\begin{array}{l}\text { Number of respondents } \\
\text { (percent of total) }\end{array}$ \\
\hline \multicolumn{2}{|l|}{ Countries with $>1 \%$ of respondents } \\
\hline United States & $200(44.4)$ \\
\hline Italy & $55(12.2)$ \\
\hline India* & $21(4.7)$ \\
\hline Brazil & $16(3.6)$ \\
\hline United Kingdom & $14(3.1)$ \\
\hline Mexico & $11(2.4)$ \\
\hline Germany & $8(1.8)$ \\
\hline Panama & $8(1.8)$ \\
\hline Canada & $7(1.6)$ \\
\hline Hong Kong & $7(1.6)$ \\
\hline Argentina & $6(1.3)$ \\
\hline Colombia & $6(1.3)$ \\
\hline Poland & $6(1.3)$ \\
\hline Cuba & $5(1.1)$ \\
\hline \multicolumn{2}{|l|}{ Countries with $<1 \%$ of respondents } \\
\hline Ecuador, Greece, Netherlands, Japan & $4(0.9)$ \\
\hline Austria, Chile, France, Indonesia*, Russia, Turkey, Vietnam* & $3(0.7)$ \\
\hline China, Malaysia, Romania, South Korea, Switzerland, Venezuela* & $2(0.4)$ \\
\hline $\begin{array}{l}\text { Afghanistan*, Australia, Azerbaijan, Bangladesh*, Belgium, Costa Rica, El } \\
\text { Salvador*, Grenada, Guatemala, Hungary, Iraq, Israel, Libya, Nicaragua*, } \\
\text { Papua New Guinea*, Puerto Rico, Rwanda*, Saudi Arabia, Serbia, } \\
\text { Somalia*, South Africa, Spain, Sri Lanka, Spain, Sweden, Syria*, Thailand, } \\
\text { Tunisia*, Yemen* }\end{array}$ & $1(0.2)$ \\
\hline
\end{tabular}

of cancelation of elective cases on univariate analysis (Table 3 , $p=.02$ ), but formal training in COVID-2 did not have a significant influence $(p=.16)$. Governmental policy for social distancing/lockdown and hospital shutdown were also significant predictors of neurosurgeons' views in support of case cancelations on univariate analysis, but only the hospital policy was significant in multi-variate analysis (Table 4, $p<0.001)$.

\section{The influence of practice setting and geography}

Respondents who practice in "for-profit" settings were less likely to experience stringent hospital mandates to cancel elective cases in both uni- and multi-variate analyses (Tables 2 and 4). In contrast, neurosurgeons in nonprofit practices were more likely to support postponement of cases $(p=.003$, Table 3$)$, but this correlation stopped short of being statistically significant on multi-variate analysis (Table $4, p=.09$ ).

Neurosurgeons in LMIC were less likely to experience hospital shutdown or support cancelation of cases (Tables 2 and 4), likely reflecting the fact that the hardest hit countries right now are non-LMIC. There were 200 respondents from the USA, where the tide of the pandemic rose most dramatically. Within the 2 weeks when the principal phase was actively accruing responses, the case numbers went from 4743 (March 16) to 142,793 (March 30). For these respondents, the date of the survey response was a positive predictor of hospital response in both uni- and multi-variate analysis $(\mathrm{OR}=1.33$ [95\% C.I. $1.11-1.61, p=.003, \mathrm{OR}=1.32$ [95\% C.I. $1.03-$ $1.69] p=.03$ respectively) and it was also a predictor of the neurosurgeon's personal view on univariate analysis (O.R. = 1.08 [95\% C.I. $1.00-1.16] p=.04$ ).

\section{Responses in the supplemental phase}

The supplemental phase of the survey received 378 responses. There were 166 respondents who attached their email addresses matchable to their responses to the principal study. Three hundred and eleven (82\%) of the supplemental respondents reported that their hospital policy had become more stringent since the start of the study, whereas $213(56 \%)$ had themselves changed their opinion about the elective case shutdown, once again indicating the fluid nature of the pandemic. 

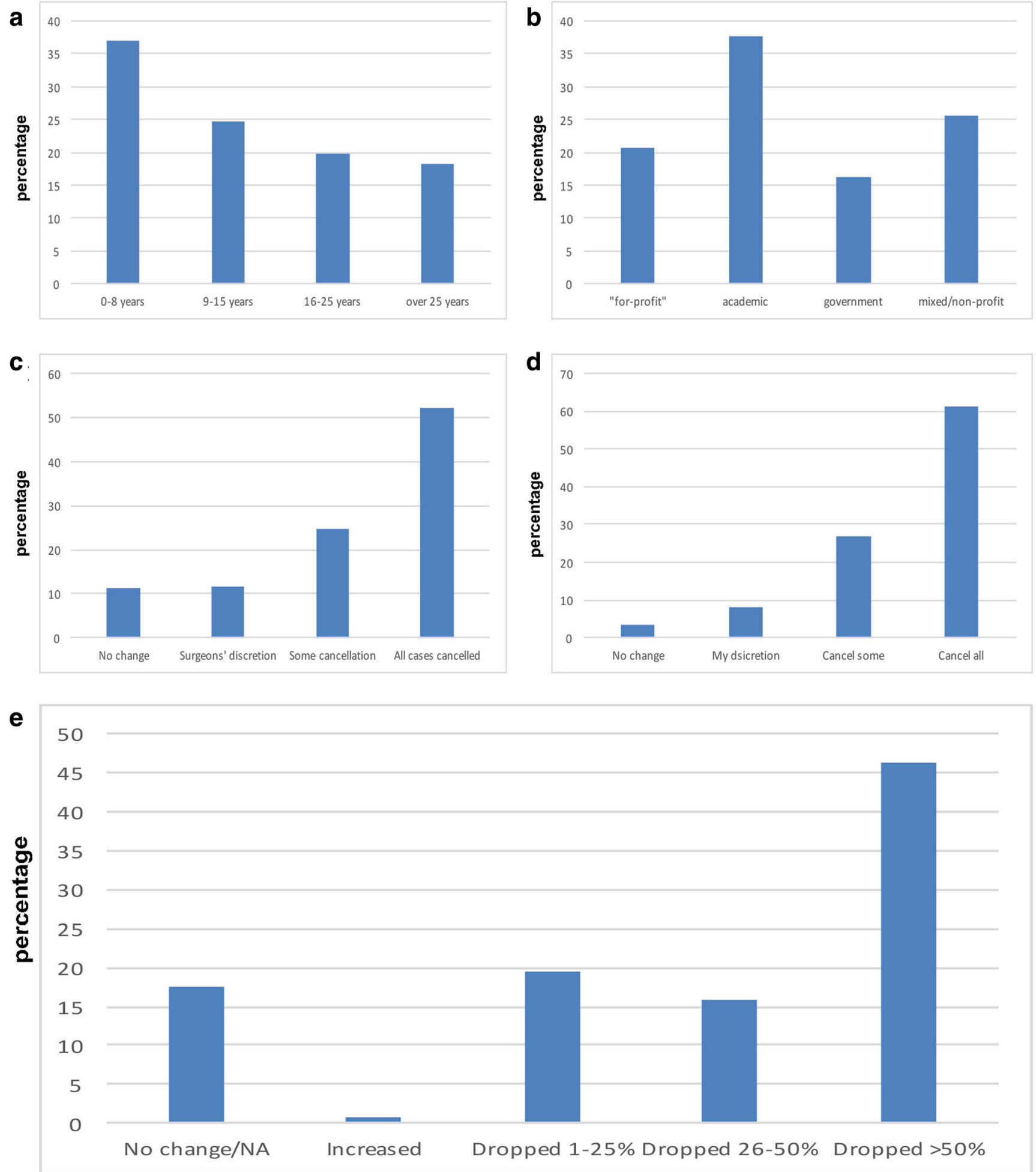

\section{$n=494$}

Fig. 1 Characteristics of respondents and their responses in the principal study. a Career phase (years in neurosurgery) of respondents. b Practice setting of respondents. $\mathbf{c}$ Hospital policy for case cancelation at the time of survey response. d Personal opinion of respondent on what ought to be done with elective cases. e Change in respondent's operative volume at the time of survey response 
Table 2 Univariable comparisons of factors influencing the hospital's response during the COVID-19 pandemic. USA, United States of America; GDP, gross domestic product; $L M I C$, low- and middle-income country; COVID-19 2019 novel coronavirus; $n$, number; $p$ value, probability value; \%, percent

Hospital response

$p$ value

\begin{tabular}{llll}
\hline $\begin{array}{l}\text { Business as } \\
\text { usual }\end{array}$ & $\begin{array}{l}\text { Postponement of elective } \\
\text { surgeries/clinic left to } \\
\text { discretion of surgeon }\end{array}$ & $\begin{array}{l}\text { Postpone some } \\
\text { elective } \\
\text { surgeries/clinic }\end{array}$ & $\begin{array}{l}\text { Postpone all elective } \\
\text { surgeries/clinic }\end{array}$ \\
\end{tabular}

\begin{tabular}{|c|c|c|c|c|c|}
\hline \multicolumn{5}{|l|}{ GDP per capita, $n / n(\%)$} & \multirow[t]{3}{*}{$<0.001$} \\
\hline LMIC & $19 / 55(34.6)$ & $13 / 55(23.6)$ & $10 / 55(18.2)$ & $13 / 55(23.6)$ & \\
\hline Non-LMIC & $34 / 428(3.3)$ & $43 / 428(10.1)$ & $109 / 428(25.6)$ & $242 / 428(56.5)$ & \\
\hline \multicolumn{5}{|l|}{ Practice setting, $n / n(\%)$} & \multirow[t]{4}{*}{0.037} \\
\hline $\begin{array}{l}\text { Non-profit charity/academic/ } \\
\text { government-employed }\end{array}$ & 34/311 (10.9) & 28/311 (9.0) & $71 / 311(22.8)$ & $178 / 311(57.2)$ & \\
\hline For-profit/private practice & 12/101 (11.9) & 20/101 (19.8) & 27/101 (26.7) & 42/101 (41.6) & \\
\hline Mixed & 9/80 (11.3) & $10 / 80(12.5)$ & $24 / 80(30.0)$ & $37 / 80(46.3)$ & \\
\hline \multicolumn{5}{|l|}{ Number of COVID-19 cases in my country, $n / n(\%)$} & \multirow[t]{4}{*}{$<0.001$} \\
\hline$<1000$ & $46 / 211(21.8)$ & $35 / 211(16.6)$ & $59 / 211(28.0)$ & $71 / 211(33.6)$ & \\
\hline $1001-5000$ & $8 / 125(6.4)$ & $13 / 125(10.4)$ & $29 / 125(23.2)$ & $75 / 125(60.0)$ & \\
\hline$>5000$ & $1 / 154(0.7)$ & $10 / 154(6.5)$ & $34 / 154(22.1)$ & $109 / 154(70.7)$ & \\
\hline \multicolumn{5}{|l|}{$\begin{array}{l}\text { Response of restaurants and shops to COVID-19 } \\
\text { in my country, } n / n(\%)\end{array}$} & \multirow[t]{4}{*}{$<0.001$} \\
\hline Business as usual & 28/51 (54.9) & $11 / 51(21.5)$ & $6 / 51(11.8)$ & $6 / 51(11.8)$ & \\
\hline A few/many have closed but some remain open & $21 / 248(8.4)$ & $37 / 248(14.9)$ & $74 / 248(29.8)$ & $116 / 248(46.8)$ & \\
\hline $\begin{array}{l}\text { Completely shut down by the government } \\
\text { (with few exceptions) }\end{array}$ & 6/193 (3.1) & $10 / 193(5.2)$ & $42 / 193(21.8)$ & $135 / 193(69.9)$ & \\
\hline \multicolumn{5}{|l|}{$\begin{array}{l}\text { Neurosurgeons' views on neurosurgical practice } \\
\text { during COVID-19 pandemic, } n / n(\%)\end{array}$} & \multirow[t]{4}{*}{$<0.001$} \\
\hline Business as usual & $13 / 17(76.5)$ & 2/17 (11.8) & $1 / 17(5.9)$ & $1 / 17(5.9)$ & \\
\hline Leave postponement to discretion of the surgeon & $7 / 41(17.1)$ & $15 / 41(36.6)$ & $11 / 41(26.8)$ & $8 / 41(19.5)$ & \\
\hline $\begin{array}{l}\text { Some or all elective surgeries/clinic should be } \\
\text { postponed }\end{array}$ & $35 / 433(8.1)$ & $41 / 433(9.5)$ & $109 / 433(25.2)$ & $248 / 433(57.2)$ & \\
\hline \multicolumn{5}{|l|}{$\begin{array}{l}\text { Change in operative volume after COVID-19, } \\
n / n(\%)\end{array}$} & \multirow[t]{5}{*}{$<0.001$} \\
\hline $\begin{array}{l}\text { Pandemic has no significant impact on my } \\
\text { country/region, business as usual }\end{array}$ & $39 / 86(45.4)$ & $23 / 86(26.7)$ & $13 / 86(15.1)$ & $11 / 86(12.8)$ & \\
\hline Dropped $1-50 \%$ & $14 / 173(8.1)$ & 23/173 (13.3) & $60 / 173(34.7)$ & 76/173 (43.9) & \\
\hline Dropped $>50 \%$ & $2 / 226(0.9)$ & $11 / 226(4.9)$ & $47 / 226(20.8)$ & $166 / 226(73.4)$ & \\
\hline Increased & $0 / 3(0.0)$ & $0 / 3(0.0)$ & $2 / 3(66.7)$ & $1 / 3(33.3)$ & \\
\hline
\end{tabular}

\section{"Risk score" for the nine cases}

The opinions on the risk of postponement are shown in Fig. 2a. The average "risk scores" were highest for the giant ophthalmic aneurysm (Q7) and cerebellar metastasis (Q3) case examples, which were both 3.5. The lowest average "risk score" was for the vestibular schwannoma (Q2) at 2.47. The percentages agreement were also highest for the giant aneurysm and cerebellar metastasis $(46.5 \%, 46.3 \%$ respectively), indicative of more agreement among the respondents on these cases. The lowest percent agreement and most disagreement was for the AVM (Q9) case scenario (31.2\%).

Excluding the risk scores of neurosurgical trainees (08 years in the field), and comparing only neurosurgeons in independent practice with the total cohort, the average risk score was not significantly different for 8 of the 9 scenarios. The only significant change occurred with the AVM case where the average risk score dropped from 2.7 (all respondents) to 2.56 (all respondents minus trainees, two-tailed Student's $t$ test, $p=0.03$ ). However, this did not have any impact on the risk ranking among the nine cases, as the AVM remained with the third lowest score, only above the pituitary adenoma and vestibular schwannoma case examples.

\section{"Urgency score" for the nine cases and the acuity index}

The opinions on the urgency to re-schedule the so-called elective cases of postponement are shown in Fig. 2b. The average "urgency scores" and percentages agreement were highest 
Table 3 Univariable comparisons of factors influencing personal views on the neurosurgeon's practice in response to COVID-19. USA, United States of America; GDP, gross domestic product; $L M I C$, low- and middle-income country; COVID-19, 2019 novel coronavirus; $n$, number; $p$ value, probability value; $\%$, percent

\begin{tabular}{|c|c|c|c|c|c|}
\hline & \multicolumn{4}{|l|}{ Personal view } & \multirow[t]{2}{*}{$p$ value } \\
\hline & $\begin{array}{l}\text { Business as } \\
\text { usual }\end{array}$ & $\begin{array}{l}\text { Leave it to my discretion } \\
\text { whether to cancel } \\
\text { surgeries/clinic }\end{array}$ & $\begin{array}{l}\text { Cancel some elective } \\
\text { surgeries/clinic }\end{array}$ & $\begin{array}{l}\text { Cancel all elective } \\
\text { surgeries/clinic }\end{array}$ & \\
\hline GDP per capita, $n / n(\%)$ & & & & & 0.002 \\
\hline LMIC & $2 / 54(3.7)$ & $11 / 54(20.4)$ & $10 / 54(18.5)$ & $31 / 54(57.4)$ & \\
\hline Non-LMIC & $14 / 429(3.3)$ & $26 / 429(6.1)$ & $119 / 429(27.6)$ & $270 / 429(63.0)$ & \\
\hline Practice setting, $n / n(\%)$ & & & & & 0.003 \\
\hline $\begin{array}{l}\text { Non-profit charity/academic/ } \\
\text { government-employed }\end{array}$ & $11 / 311(3.5)$ & $14 / 311(4.5)$ & $84 / 311(27.0)$ & $202 / 311(65.0)$ & \\
\hline For-profit/private practice & $5 / 102(4.9)$ & $17 / 102(16.7)$ & $25 / 102(24.5)$ & $55 / 102(53.9)$ & \\
\hline Mixed & $1 / 79(1.3)$ & $10 / 79(12.7)$ & $23 / 79(29.0)$ & $45 / 79(57.0)$ & \\
\hline $\begin{array}{l}\text { Number of COVID-19 cases in my } \\
\text { country, } n / n(\%)\end{array}$ & & & & & 0.018 \\
\hline$<1000$ & $10 / 211(4.7)$ & 24/211 (11.4) & $53 / 211(25.1)$ & $124 / 211(58.8)$ & \\
\hline $1001-5000$ & $5 / 125(4.0)$ & $4 / 125(3.2)$ & $44 / 125(35.2)$ & $72 / 125(57.6)$ & \\
\hline$>5000$ & $2 / 154(1.3)$ & $13 / 154(8.5)$ & $35 / 154(22.7)$ & $104 / 154(67.5)$ & \\
\hline $\begin{array}{l}\text { Response of restaurants and shops to } \\
\text { COVID-19 in my country, } n / n(\%)\end{array}$ & & & & & $<0.001$ \\
\hline Business as usual & $7 / 51(13.7)$ & 7/51(13.7) & $16 / 51(31.4)$ & $21 / 51(41.2)$ & \\
\hline A few/many have closed but some remain open & $10 / 249(4.0)$ & $24 / 249(9.6)$ & $68 / 249(27.3)$ & $147 / 249(59.0)$ & \\
\hline $\begin{array}{l}\text { Completely shut down by the government } \\
\text { (with few exceptions) }\end{array}$ & $0 / 192(0.0)$ & $10 / 192(5.2)$ & $48 / 192(25.0)$ & $134 / 192(69.8)$ & \\
\hline Training about COVID-19, $n / n(\%)$ & & & & & 0.157 \\
\hline I have not dedicated time to learn about COVID-19 & $1 / 33(3.0)$ & $2 / 33(6.0)$ & $15 / 33(45.5)$ & $15 / 33(45.5)$ & \\
\hline $\begin{array}{l}\text { I learned on my own; I know enough to make } \\
\text { professional decisions related to COVID-19 }\end{array}$ & $11 / 315(3.5)$ & $30 / 315(9.5)$ & $74 / 315(23.5)$ & $200 / 315(63.5)$ & \\
\hline $\begin{array}{l}\text { I received formal training which my } \\
\text { hospital/university required }\end{array}$ & $5 / 141(3.6)$ & 9/141 (6.4) & $43 / 141(30.5)$ & $84 / 141(59.6)$ & \\
\hline Hospital policy on COVID-19, $n / n(\%)$ & & & & & $<0.001$ \\
\hline Business as usual & $13 / 55(23.7)$ & $7 / 55(12.7)$ & $12 / 55(21.8)$ & $23 / 55(41.8)$ & \\
\hline $\begin{array}{l}\text { Postponement left to discretion of the surgeon; no } \\
\text { formal policy in place }\end{array}$ & $2 / 58(3.4)$ & $15 / 58(25.9)$ & $15 / 58(25.9)$ & $26 / 58(44.8)$ & \\
\hline Some or all elective surgeries/clinic are postponed & $2 / 378(0.5)$ & $19 / 378(5.0)$ & $105 / 378(27.8)$ & $252 / 378(66.7)$ & \\
\hline
\end{tabular}

Odds ratio $>1=$ positive independent predictor and $<1=$ negative independent predictor of hospital cancelation of some or all surgeries

once again for the cerebellar metastasis (Q3 4.22, 37.0\%)) and giant ophthalmic aneurysm (Q7 3.96, 36.4\%). By multiplying the average risk score from the principal phase to the average urgency score of the supplemental phase, the acuity index for each case was generated and ranked (Table 5). According to the total cohort in the full study, the acuity rank was highest for the cerebellar metastasis $(\mathrm{AI}=14.8)$ and lowest for the vestibular schwannoma $(\mathrm{AI}=5.85)$.

In sub-group analysis for the 166 respondents who were identifiable in both the principal and supplemental phases, a personal acuity index was calculated by multiplying the individual respondent's risk and urgency scores for each case. The average of these $\left(\mathrm{PAI}_{166}\right)$ generated the same ranking of the nine cases except for one pair; the GBM and aneurysm cases switched positions. However, the $\mathrm{PAI}_{166}$ for these two cases were not statistically different (14.2 vs. 14.0, two-tailed $t$ test, $p=.74)$.

\section{Discussion}

\section{Reasons behind the impact of COVID-19 on neurosurgery}

Nearly half of the respondents in this study for around the world $(46.1 \%)$ reported that their operative volume has dropped more than $50 \%$ during the pandemic. Even more neurosurgeons $(61.4 \%)$ opined that all elective cases should 
Table 4 Multivariable model of the independent factors influencing hospital response to COVID-19 and neurosurgeons' personal views in support of postponement of non-emergent cases. COVID-19, 2019 novel coronavirus; C.I., confidence interval, $p$ value, probability value

\begin{tabular}{|c|c|c|c|c|c|c|c|}
\hline \multicolumn{4}{|l|}{ Hospital response } & \multicolumn{4}{|l|}{ Personal view } \\
\hline Variable & $\begin{array}{l}\text { Odds } \\
\text { ratio }\end{array}$ & 95\% C.I. & $p$ value & Variable & $\begin{array}{l}\text { Odds } \\
\text { ratio }\end{array}$ & 95\% C.I. & $p$ value \\
\hline \multicolumn{8}{|l|}{ GDP } \\
\hline Non-LMIC & Ref & Ref & Ref & & & & \\
\hline LMIC & 0.483 & $0.356-0.914$ & 0.025 & & & & \\
\hline \multicolumn{8}{|l|}{$\begin{array}{l}\text { Personal views on neurosurgical } \\
\text { practice during COVID-19 pandemic }\end{array}$} \\
\hline Business as usual & Ref & Ref & Ref & & & & \\
\hline $\begin{array}{l}\text { Postponement left to discretion } \\
\text { of the surgeon }\end{array}$ & 5.821 & $1.394-24.301$ & 0.016 & & & & \\
\hline $\begin{array}{l}\text { Some or all elective surgeries/clinic } \\
\text { should be postponed }\end{array}$ & 15.481 & $4.196-57.124$ & $<0.001$ & & & & \\
\hline \multicolumn{8}{|l|}{$\begin{array}{l}\text { Response of restaurants and shops } \\
\text { to COVID-19 in my country, } n / n(\%)\end{array}$} \\
\hline Business as usual & Ref & Ref & Ref & & & & \\
\hline $\begin{array}{l}\text { A few/many have closed but some } \\
\text { remain open }\end{array}$ & 3.233 & $1.571-6.649$ & 0.001 & & & & \\
\hline $\begin{array}{l}\text { Completely shut down by the } \\
\text { government } \\
\text { (with few exceptions) }\end{array}$ & 5.908 & $2.665-13.099$ & $<0.001$ & & & & \\
\hline Practice setting & & & & Practice setting & & & \\
\hline $\begin{array}{l}\text { Non-profit/academic/ } \\
\text { government-employed }\end{array}$ & Ref & Ref & Ref & $\begin{array}{l}\text { Non-profit/academic } \\
\text { /government-employed }\end{array}$ & 1.402 & $0.952-2.066$ & 0.088 \\
\hline \multirow[t]{4}{*}{ For-profit/private practice } & 0.578 & $0.381-0.878$ & 0.010 & For-profit/private practice & Ref & Ref & Ref \\
\hline & & & & Hospital policy on COVID-19 & & & \\
\hline & & & & Business as usual & Ref & Ref & Ref \\
\hline & & & & $\begin{array}{l}\text { Some or all elective } \\
\text { surgeries/clinics are } \\
\text { postponed }\end{array}$ & 2.908 & $1.822-4.639$ & $<0.001$ \\
\hline
\end{tabular}

be postponed. Whereas there are many reasons to justify this postponement, the most important one, and the only one cited in the American College of Surgeons' monumental recommendation [7, 8], is on a societal level: to preserve essential supplies, such as ventilators, for the avalanche of patients who will overwhelm resources in the predictable future.

Objections against such an unprecedented recommendation is perhaps equally predictable [9]. Indeed, our data indicated that hospitals staffed by private-practice neurosurgeons were less likely than non-profit hospitals to mandate expansive cancelation of elective cases in the weeks following the ACS recommendation. And predictably, neurosurgeons working in the "for-profit" setting were also less likely to be in favor of broadly shutting down surgeries.

In the rapidly changing circumstances of the pandemic, only days after the ACS issued its document, other reasons started to emerge, justifications for postponement which are more on a personal level. As the case numbers surged, hospitals quickly became "breeding grounds" for the SARS-CoV-2 virus even as social distancing mitigated its spread elsewhere in society. When the Center of Medicare and Medicaid Services issued its recommendation, "limiting exposure of patients to the ...virus" was cited in the first paragraph as a means to "aggressively address COVID-19" [10].

As personal protective equipment ran scarce, the preservation of hospital staff quickly become another strong reason to defer non-emergent procedures [13]. In their warning about endonasal surgeries during the pandemic, the "Stanford protocol" cited a report from Wuhan, China in which multiple members (>14) in and around a transphenoidal procedure became infected, thought to be due to high viral shedding from the nasal and oropharyngeal cavity [14].

Taken together, postponing elective surgeries is not only a reasonable strategy, it seems to be the only rational path for neurosurgeons until the end of the pandemic $[3,15]$. The data from our US respondents indicated that even within the short 


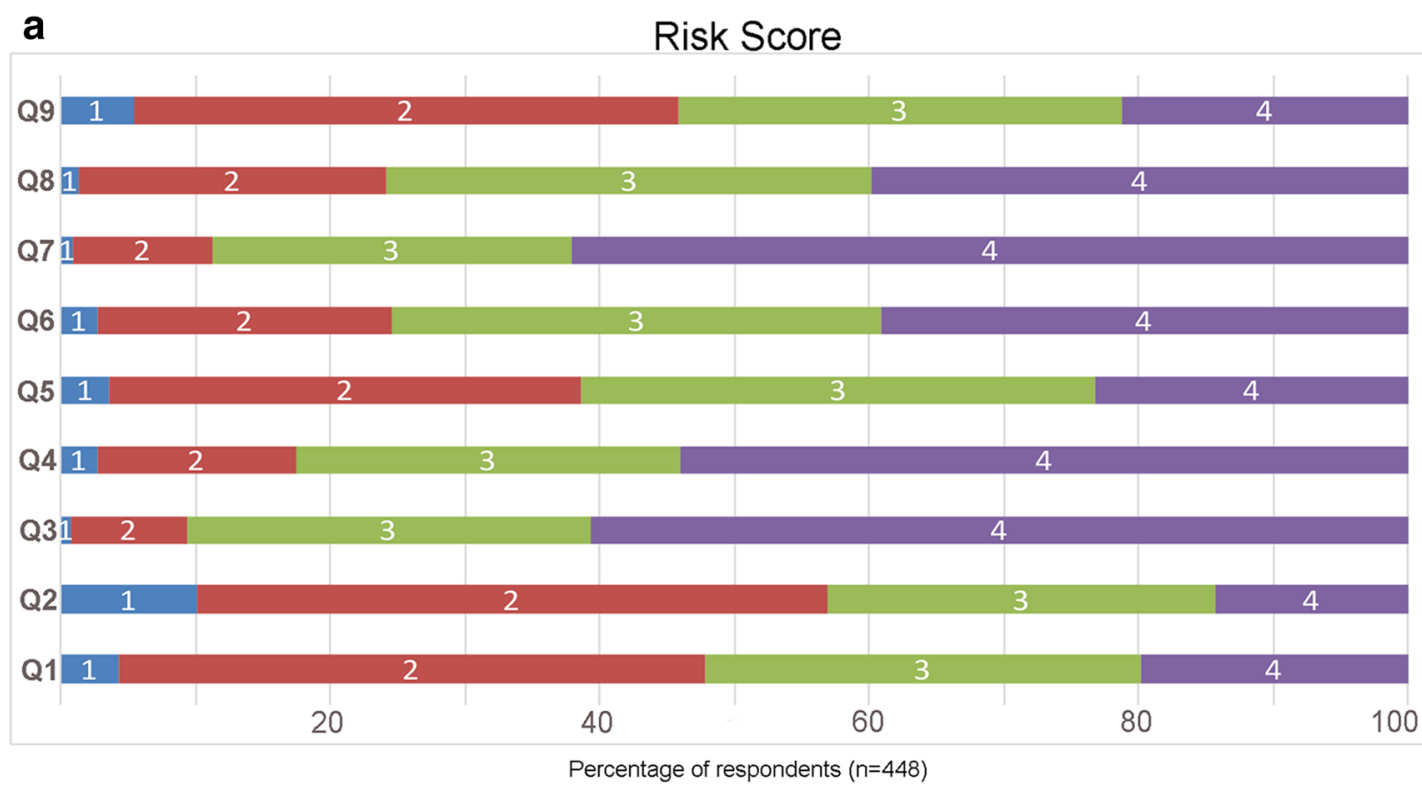

Ave \%agreement

$2.70 \quad 31.2$

$3.14 \quad 34.1$

$3.50 \quad 46.5$

$3.12 \quad 33.2$

$2.81 \quad 32.2$

$3.39 \quad 39.3$

$3.51 \quad 46.3$

$2.47 \quad 33.1$

$2.68 \quad 33.5$

b

Urgency Score

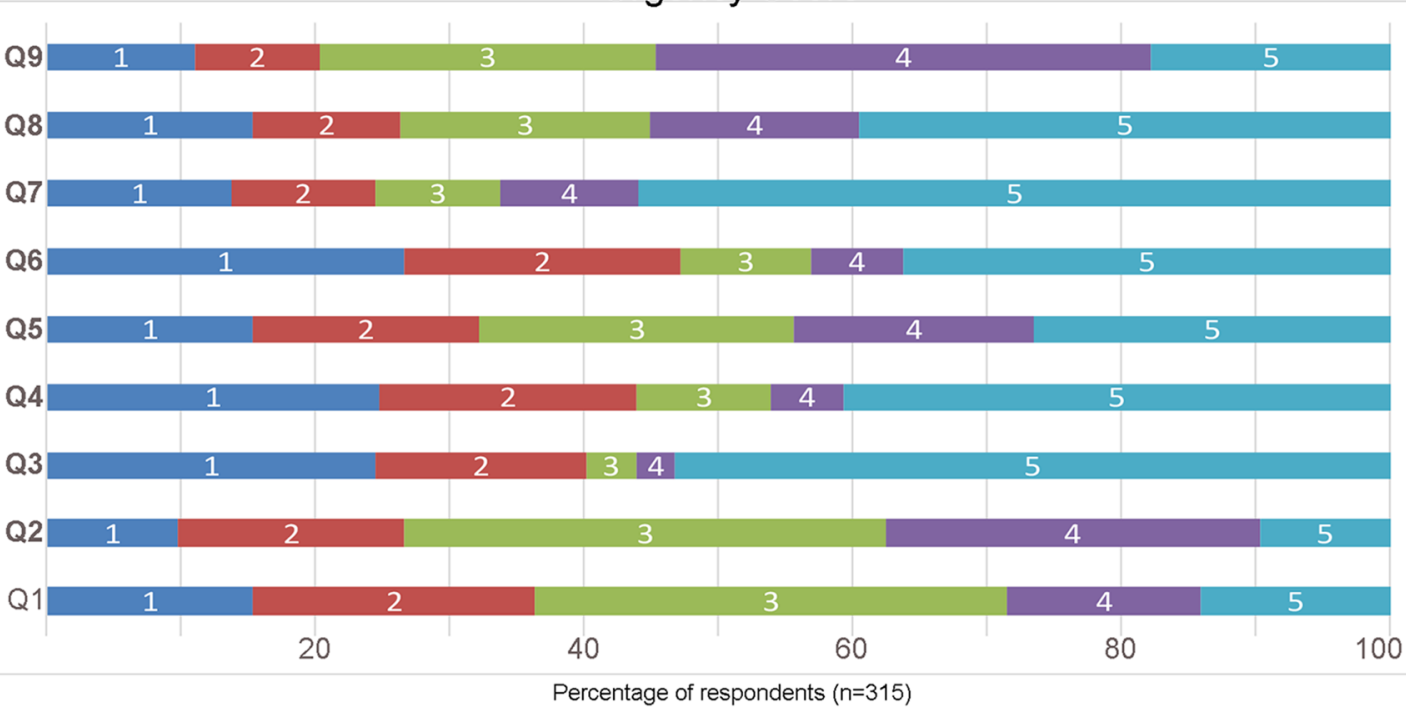

Ave \%agreement

$2.48 \quad 24.9$

$3.44 \quad 24.9$

$3.96 \quad 36.4$

$3.76 \quad 25.8$

$3.08 \quad 25.8$

$3.86 \quad 27.6$

$4.22 \quad 37.0$

$2.37 \quad 25.0$

$2.80 \quad 22.8$

Percentage of respondents $(n=315)$

Fig. 2 Responses to the nine case scenarios. a Respondents were asked to stratify the risk of postponing surgery for each case into four tiers from "no risk" (1) to "cannot postpone" (4). The average "risk score" and percentage agreement are shown on the right. b Respondents were asked to stratify the urgency to re-schedule the same nine cases into 5 tiers from "leave until the end of the pandemic" (1) to "case already done" (5). The average "urgency score" and percentage agreement are shown on the right. (NB: Since there are a different number of options in "risk" and "urgency," neither the average or percentage agreement are not comparable between "risk" and "urgency")
2 weeks of the principal study, the date of the response was a positive predictor of both the hospitals' response and neurosurgeons' opinion towards more stringent shutdown.

\section{What cases to postpone}

Having trained for decades to earn the privilege to operate, more likely to "run towards the fire" than away from it, and always preferring action over being idle, any neurosurgeon is likely to be unfamiliar and uncomfortable with that idea that postponing her or his work is beneficial to society. When solving a neurosurgical problem means the possibility of deadly infection for both patient and staff, the risk/benefit calculation has become completely foreign. To help define what constitutes a legitimate procedure that should be done despite the pandemic, several institutions have published categories of procedures to be considered "emergent." [16-20] But neurosurgeons are trained to recognize emergencies, and our data reflected that the strongest agreement among our respondents was on the 2 case scenarios with highest risk and urgency scores (i.e. giant aneurysm and cerebellar metastasis, Table 2 Q7, Q3). In fact, for emergent, life-preserving cases, the trickier question is which to defer, as surgeons became 
Table 5 The acuity index was calculated by multiplying the average risk score (from the principal study) to the average urgency index (from the supplement study). The rank of the $\mathrm{AI}$ in the group of nine cases is shown in parenthesis. The $\mathrm{PAI}_{166}$ was calculated for each case as follows: for each respondent who identifiably completed both parts of the study, the risk score (principal phase) was multiplied to same respondent's urgency score for the same case (supplement phase) to generate a personal acuity index (PAI) for that case. The average for the 166 respondents was recorded under $\mathrm{PAI}_{166}$ (rank in parenthesis)

\begin{tabular}{lllll}
\hline & Ave risk score $(n=448)$ & Ave urgency score $(n=315)$ & Acuity index (rank) & PAI $166($ rank $)$ \\
\hline Cerebellar Met & 3.51 & 4.22 & $14.8(1)$ & $15.5(1)$ \\
Giant Aneurysm & 3.50 & 3.96 & $13.9(2)$ & $13.9(3)$ \\
GBM & 3.39 & 3.86 & $13.1(3)$ & $14.2(2)$ \\
Spinal Met & 3.12 & 3.76 & $11.7(4)$ & $12.3(4)$ \\
Carotid & 3.14 & 3.45 & $10.8(5)$ & $10.9(5)$ \\
C45 disc & 2.81 & 3.09 & $8.68(6)$ & $7.73(6)$ \\
Pituitary Tumor & 2.68 & 2.80 & $7.50(7)$ & $7.87(7)$ \\
AVM & 2.70 & 2.48 & $6.70(8)$ & $6.67(8)$ \\
VS & 2.47 & 2.37 & $5.85(9)$ & $6.28(9)$ \\
\hline
\end{tabular}

increasingly concerned that some operations may create ventilator-dependent patients without meaningful recovery, unfortunate always, but unjustifiable when resources are scarce during the pandemic.

Regarding non-emergent operations, the ACS document which started the elective case shutdown in the USA was amended to include an "Elective Surgery Acuity Scale," meant as a guideline to re-schedule cases [8]. Despite thorough searches, we were unable to locate the scale in any published studies, and moreover, the application of the scale to neurosurgery is questionable since a single, massively-broad description, "Neurosurgery," was placed in "Tier 3a: do not postpone." The EANS published an "Adapted Elective Surgery Acuity Scale" [17] which is more helpful, but even in this, procedures are grouped in a large disease categories such as "unruptured aneurysm," which incidentally is in Tier 2 "postpone if possible." Since not all unruptured aneurysms are alike, there remains a vast amount of ambiguity. Applying this scale to our 9 scenarios, the $\mathrm{C} 45$ stenosis case in our study, in 6th place in the acuity rank per our respondents (Table 5), would have been placed in tier 1 and postponed indefinitely, whereas the pituitary adenoma and vestibular schwannoma, in the 7th and 9th ranks, would have been placed in tier 2 and gone ahead of it. The giant aneurysm, in the 2 nd position in our acuity rank just behind the cerebellar metastasis, would have been in tier 2 and postponed for treatment, while the AVM, in the 8th position, would also be in tier 2 indistinguishable from the aneurysm.

A strategic scheme is perhaps more useful. If the line of thinking can follow a logical progression, it can then be applied to any case with nuanced, yet critical clinical information, neglected in broad categorizations. We examined the way our respondents ranked the 9 hypothetical scenarios in this study and "reverse engineered" a strategic scheme that would duplicate that ranking. There are two orthogonal axes that make up this scheme, two lines of thinking that intersect.
In the first, one considers the next adverse event that is likely to occur during postponement of surgery, and this is the risk that was assessed in principal phase. Whether the adverse event occurs through disease progression or pure chance is not as important as the severity of the consequence, which we rank from "significant focal neurological deficit," to "severe focal neurological deficit," to "coma," and then "death." The other line of thinking involves time, and this was assessed in the supplemental phase. Does the next predictable adverse event have a 50/50 chance of occurring in 2 days, 1 week, 2 weeks, 1 month, or 2 months?

Using the cerebellar metastasis case as an example, the next adverse event is likely hydrocephalus from disease progression, leading possibly to coma. This event may not happen in 2 days' time, but there may well be a 50/50 chance of it happening within 1 week. With this "educated guess," one can place a marker under " 3 " on the horizontal axis and next to " 4 " on the vertical on Fig. 3. This position is in very close proximity to " $\mathrm{A}$," where our study data positioned the same case. One can apply these two lines of thinking to any clinical scenario and place the result as a marker on Fig. 3. If the marker lands in blue, then the procedure can reasonably be postponed until the end of the pandemic. If red, the operation should probably happen soon. A marker in purple denotes a case that can be postponed until hospital resources, as well as personnel and patient safety are reasonably assured. Since trauma procedures have dropped significantly as a side-effect of social distancing $[5,6]$, it not unreasonable to believe that when "flattening the curve" finally happens, some of the cases landing the purple zone can proceed before they turn into emergencies.

\section{Limitations of the study}

While the use of social media allows for rapid dissemination and collection of data, there are distinct challenges controlling 


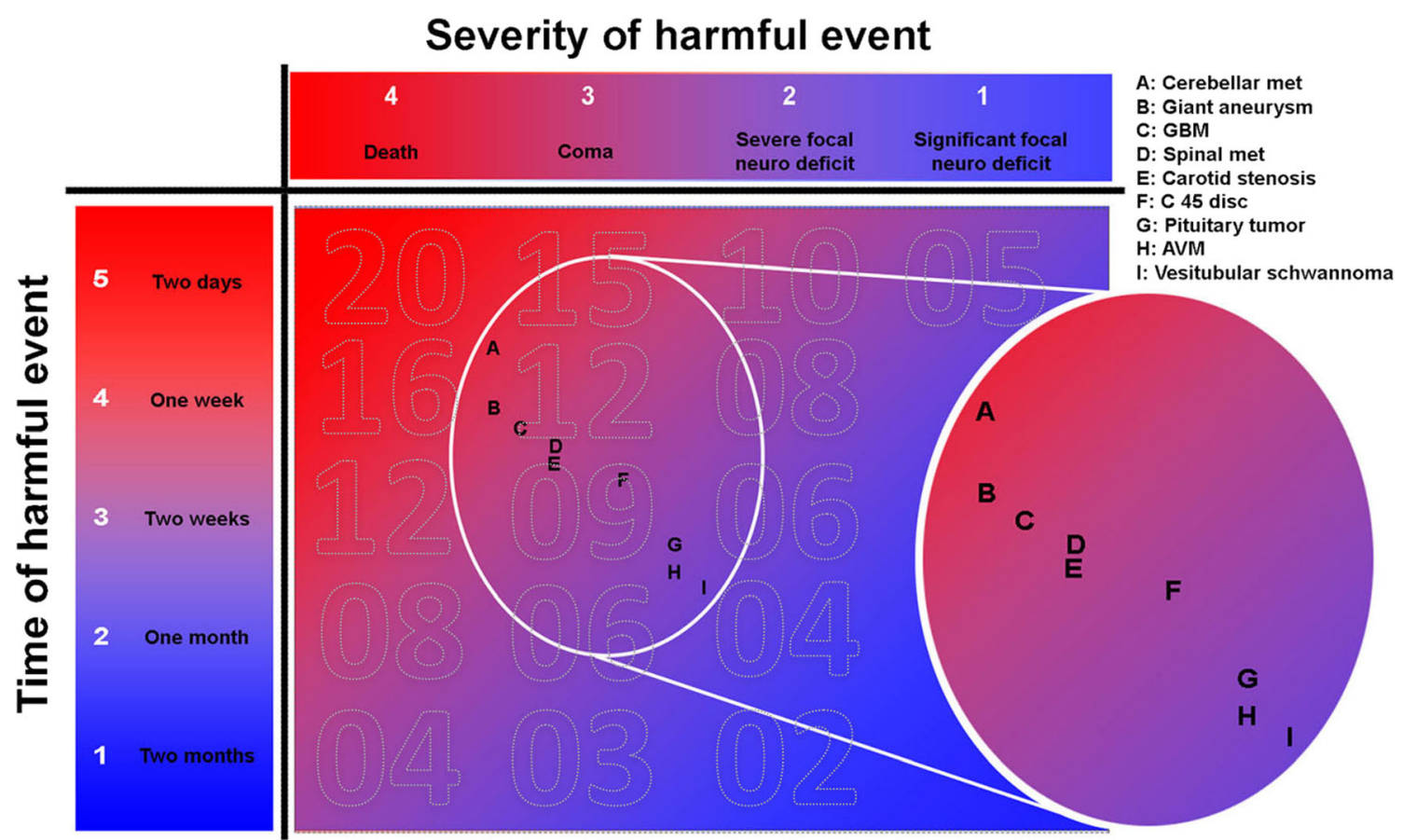

Fig. 3 A proposed strategic scheme. The scheme consists of two orthogonal lines of thinking, one related to the next predictable adverse event (either from disease progression or by chance), and the other related to the timing of this event. The nine case scenarios, A-I, are plotted onto

for who takes the survey. To help overcome these limitations, private social media networks were utilized specifically targeting international neurosurgeons to participate in the surveys. As with all studies involving surveys from volunteers, selection bias is hard to avoid and may not necessarily represent majority opinions of every neurosurgeon around the world. As polling does for elections, this study only "spot checks" the opinions of neurosurgeons and their practice conditions.

Among the respondents, the proportion of early-career neurosurgeons was greater than those with more experience. It is likely that some respondents interpreted the "years in neurosurgery" question to mean post-training, even though the survey was meant to include trainees. Fortunately, as pointed out in the results section, excluding neurosurgeons who reported " $0-8$ years" in the field did not alter the scores significantly.

Since the two-part survey was conducted anonymously and an email identifier was voluntary, only 166 respondents could be verified as completing both phases. The other respondents may or may not be the same surgeons in both phases, but the cumulative responses, in aggregate, would reflect the impact of the virus pandemic on current neurosurgical practices.

The hypothetical cases selected may not realistically reflect what every survey respondent regularly manages within their scope of practice. Similarly, it is impossible to quantify the respective expertise of each neurosurgeon respondent, which may also contribute to study bias. However, we specifically avoided asking a panel of "experts" to adjudicate our the field according to the average "risk score" and "urgency score" generated from our study (Table 5). Numbers in field: estimated acuity index

scenarios, as this would create an artificial setting unrealistic in the "real world," where neurosurgeons make daily decisions without expert advice. We could have asked our respondents to rank the acuity of the 9 scenarios to save a step in the study. Instead, we chose to ask them about the risk of postponement and the urgency to re-schedule because these questions are more realistic. Routinely, neurosurgeons made decisions on individual clinical scenarios, and triaging nine cases at once seemed artificial.

\section{Conclusion}

The COVID-19 pandemic continues to have a significant impact on healthcare systems worldwide. To care for the massive numbers of COVID patients, many hospital systems and surgeons are focused on conserving resources by limiting elective surgical procedures. During this study, conducted during the peak of the pandemic in Western Europe, we sought to determine how COVID-19 has disrupted the practice of neurosurgeons globally and affected the decision-making in triaging neurosurgical cases. A majority of respondents reported that all elective cases and clinics were re-scheduled. Government policy for strict social distancing and higher number of COVID-19 cases were predictors of hospital policy and neurosurgeons' views on canceling cases, while "for-profit" practices and neurosurgeons in LMIC were less likely to experience strict hospital mandates for postponement. The survey 
responses to non-emergent case scenarios were used to develop an acuity index, which indicated that neuro-oncology cases, as well as select vascular cases, have high acuity. A strategic scheme was created as a possible guideline for sensible triaging of non-emergent neurosurgical cases, so that global neurosurgeons can continue to serve their patients without harming them either neurologically through delaying surgery, or by unnecessarily exposing them to the deadly virus at the pinnacle of the COVID tide.

\section{Compliance with ethical standards}

Conflict of interest The authors declare that they have no conflict of interest.

\section{References}

1. Mao L, Wang MD, Chen SC, He QW, Chang J et al (2020) Neurological manifestations of hospitalized patients with COVID19 in Wuhan, China: a retrospective case series study. Lancet Neurology reprint. https://papers.ssrn.com/sol3/papers.cfm? abstract_id=3544840 accessed 01 Apr 2020

2. Poyiadji N, Shahin G, Noujaim D, Stone M, Patel S et al (2020). COVID-19-associated acute hemorrhagic necrotizing encephalopathy: CT and MRI. Images in Radiology https://oi.org/10.1148/ radiol.2020201187. Accessed 03 Apr 2020

3. Sterpeti AV (2020). Lessons learned during the COVID-19 virus pandemic. https://www.journalacs.org/article/S1072-7515(20) 30262-3/pdf. https://doi.org/10.1016/j.jamcollsurg.2020.03.018. Accessed 01 Apr 2020

4. Global Neuro Foundation (2020) Global neuro- neurosurgical special report 2020-nCoV-neurosurgical practice during the pandemiclearnings from the world's most affected countries. https://mailchi. mp/globalneuro/special_report_2019_ncov. Accessed 04 Apr 2020

5. International Webinar Symposium: "Impact of COVid-19 on Neurosurgery" (2020). https://www.youtube.com/watch?v= NIDWcrqkMIU. Accessed 04 Apr 2020

6. Mount Sinai Health System Department of Neurosurgery Intercontinental Grand Rounds (2020) Confronting COVID-19 lecture series. https://www.youtube.com/watch? $\mathrm{v}=\mathrm{d} 3 \mathrm{~A} 62 \mathrm{Um} \_\mathrm{CIs}$. Accessed 01 Apr 2020

7. American College of Surgeons (2020) COVID-19: recommendations for management of elective surgical procedures. https://www. facs.org/about-acs/covid-19/information-for-surgeons. Accessed 01 Apr 2020
8. American College of Surgeons (2020) COVID-19: guidance for triage of non-emergent surgical procedures. https://www.facs.org/ covid-19/clinical-guidance/triage. Accessed 01 Apr 2020

9. American Hospitals of America (2020) Re: elective surgeries and COVID-19. https://www.aha.org/lettercomment/2020-03-15-ahaletter-surgeon-general-re-elective-surgeries-and-covid-19. Accessed 01 Apr 2020

10. Center for Medicare \& Medicaid Services (2020) CMS adult elective surgery and procedures recommendations: limit all nonessential planned surgeries and procedures, including dental, until further notice. https://www.cms.gov/files/document/31820-cmsadult-elective-surgery-and-procedures-recommendations.pdf. Accessed 01 Apr 2020

11. World Bank. Databank. https://data.worldbank.org/country/ Accessed March 16, 2020

12. World Meter: Coronavirus. https://www.worldometers.info/ coronavirus/ Accessed April 6, 2020

13. Chang DX, Huiwen RA, Sharma L, Dela Cruz CS (2020) Protecting health-care workers from subclinical coronavirus infection. Lancet Respir Med Mar 8(3):e13

14. Patel, ZM, Fernandez-Miranda J, Hwang, PH, Nayak JV, Dodd, R, Sajjadi H, Jackler, R (2020) Precautions for endoscopic transnasal skull base surgery during the COVID-19 pandemic https://www. entnet.org/sites/default/files/uploads/covid-19_endosb lettertoeditor_neurosurgery_update3.23.20.pdf. Accessed 01 Apr 2020

15. Raphael, T (2020). Why surgeons don't want to operate right now. https://www.bloomberg.com/opinion/articles/2020-03-24/thecoronavirus-crisis-is-putting-surgeons-at-risk-too. Accessed 01 Apr 2020

16. Burke J, Chan AK, Mummaneni V, Dean C, et al (2020) The coronavirus disease 2019 global pandemic: a neurosurgical treatment algorithm. Neurosurgery. https://doi.org/10.1093/neuros/nyaa116. Accessed 04 Apr 2020

17. European Association of Neurological Surgeons (2020) Triaging emergent neurosurgical procedures during the COVID-19 outbreak. http://cdnymawscom/wwweansorg/resource/resmgr/documents/ corona/eans_advice2020_coronapdf Accessed 01 Apr 2020

18. German Society for Neurosurgery (2020) Statement defining spectrum of non-elective surgical interventions. https//wwwdgncde/ gesellschaft/aktuelles/statements/ Accessed 29 Mar 2020

19. Hong Kong Neurosurgical Society (2020) COVID-19 statement. https://wwwnsorghk/post/hkns-covid-19-statement Accessed 01 Apr 2020

20. Zoia C, Bongetta D, Veiceschi P et al (2020). Neurosurgery during the COVID-19 pandemic: update from Lombardy, northern Italy. Acta Neurochir https://doi.org/10.1007/s00701-020-04305-w. Accessed 01 Apr 2020

Publisher's note Springer Nature remains neutral with regard to jurisdictional claims in published maps and institutional affiliations. 